\title{
A ATUAÇÃO DA CONTABILIDADE GERENCIAL COMO MÉTODO BENÉFICO NAS EMPRESAS
}

\section{ARTIGO ORIGINAL}

RIBEIRO, Marcilene Sales ${ }^{1}$

RIBEIRO, Marcilene Sales. A atuação da contabilidade gerencial como método benéfico nas empresas. Revista Científica Multidisciplinar Núcleo do Conhecimento. Ano. 07, Ed. 02, Vol. 03, pp. 134-146. Fevereiro de 2022. ISSN: 2448-0959, Link de acesso: $\quad$ https://www.nucleodoconhecimento.com.br/contabilidade/benefico-nasempresas

\section{RESUMO}

A contabilidade gerencial é um processo que produz informações para as diversas partes interessadas da empresa tais como: os investidores, órgãos governamentais, credores, dentre outros e, através destas informações, são tomadas as decisões com mais segurança, fazendo com que a empresa cresça e se torne competitiva. Assim, se tem como a seguinte pergunta de pesquisa: como é a atuação da contabilidade gerencial na tomada de decisão no meio empresarial? O objetivo geral é analisar suas características, bem como a aplicação e os benefícios da Contabilidade Gerencial para empresas. A metodologia utilizada para realizar a pesquisa foi descritiva e explicativa. Quanto aos meios, a pesquisa foi bibliográfica, buscando a definição e o alcance do problema levantado, por meio de artigos, de livros e de sites especializados. Ao longo da elaboração da pesquisa, foi possível concluir que a contabilidade gerencial se constitui como um instrumento relevante para o processo de tomada de decisões, visto que, a literatura consultada é unânime em afirmar que a

\footnotetext{
${ }^{1}$ MBA Controladoria, auditoria e perícia contábil, MBA em gestão de contabilidade e finanças empresariais, Graduação em Ciências Contábeis. ORCID: 0000-0001-62590139.
} 
contabilidade, como sistema de informação e avaliação patrimonial, provê aos usuários informações econômicas, financeiras e patrimoniais para respaldar as decisões.

Palavras-Chave: Tomada de decisões, Contábil, Gerencial.

\section{INTRODUÇÃO}

A contabilidade gerencial tem um sentido muito mais amplo na vida das empresas, chegando a ser uma das principais fontes de orientação dos gestores. A contabilidade gerencial, como parte integrante do processo de gestão, adiciona valor distintivamente pela investigação contínua sobre a efetividade da utilização dos recursos pelas organizações - na criação de valor para os acionistas e outros credores (FERREIRA, 2004).

O tema foi desenvolvido devido a necessidade de ressaltar a importância da contabilidade gerencial e sua finalidade em processar informações vantajosas aos usuários da ciência contábil para o procedimento de tomada de decisão. Visou-se, também, demonstrar a contabilidade gerencial como uma ferramenta vital à administração das empresas.

Assim, se tem como pergunta de pesquisa: como é a atuação da contabilidade gerencial na tomada de decisão no meio empresarial?

Um conhecimento mais aprofundado para o desenvolvimento do controle gerencial pode proporcionar condições de atuação, o desenvolvimento de mecanismos e sua implementação, de maneira substanciosa, de acordo com a necessidade das organizações. Dessa forma, este estudo tem como objetivo geral: analisar suas características, bem como a aplicação e os benefícios da Contabilidade Gerencial para empresas.

Os objetivos específicos foram: definir sobre os termos da Contabilidade Gerencial e sua finalidade; evidenciar a importância da contabilidade gerencial como fontes de

RC: 106869

Disponível em: https://www.nucleodoconhecimento.com.br/contabilidade/beneficonas-empresas 
informações; identificar etapas do processo para a tomada das decisões por meio da Contabilidade Gerencial.

A metodologia utilizada para realizar a pesquisa, foi descritiva e explicativa. Para o alcance dos objetivos, propôs-se a realização de uma pesquisa do tipo descritiva e, como técnica, uma análise bibliográfica. A pesquisa descritiva, conforme Gil (1999) apud Bertucci (2012), "tem como objetivo primordial a descrição das características de determinada população ou fenômeno ou, então, o estabelecimento de relações entre variáveis".

A contabilidade gerencial ainda sofre resistência por parte de algumas empresas que necessitam dessas informações gerenciais para o processo de tomada de decisão. Partindo do pressuposto de que nenhuma empresa pode permanecer sem uma gestão apropriada de recursos, informações e processos de tomada de decisões, a compreensão de como a contabilidade gerencial pode contribuir os gestores e as companhias a serem mais efetivos, torna-se essencial (FERREIRA, 2004).

\section{REVISÃO DA LITERATURA}

A Contabilidade Gerencial pode ser avaliada como um conjunto de informações atribuídas para apoiar seus usuários no processo de tomada de decisões. Desde a idade antiga, com as transações ocorridas nas organizações remotas e a demanda de troca de produtos, nota-se que já eram populares controles gerenciais simples. Com a Revolução industrial, ocorreu um crescimento na prática da Contabilidade devido à necessidade das entidades buscarem um aperfeiçoamento em suas informações para obterem uma melhor administração e um eficiente controle em seus negócios (FIGUEIREDO; CAGGIANO, 1997).

A contabilidade gerencial exerce um papel relevante na empresa, o de fornecer à administração informações úteis que serão manuseadas no processo decisório, de verificar se as mudanças organizacionais alteram os hábitos e rotinas e o de auxiliar na melhoria da qualidade da informação fornecida aos gestores (GITMAN, 2000). 
Conforme Marion (2005, p. 23-24), a contabilidade gerencial é o instrumento que auxilia a administração na tomada de decisões assertivas. Conta com a coleta de dados econômicos, mensura-os monetariamente, registra-os e sumariza-os em forma de relatórios ou de comunicados, que contribuem para tomada de decisões. As decisões sobre produção, marketing, investimentos, financiamentos, custos, não são tomadas sem a contabilidade.

Contabilidade gerencial é a área da contabilidade onde se procura estabelecer e determinar o futuro, o desenvolvimento de uma instituição. Ela trabalha alinhada com planejamento estratégico, sendo relevante para qualquer tipo de instituição. É através dessa ferramenta que se tem controle de todas as atividades financeiras, como: empréstimos, financiamentos, contratações, investimentos, desinvestimentos etc. A empresa que não possui o controle sobre tais atividades sofre consequências financeiras e tributárias (GITMAN, 2000).

Segundo Padoveze (2012), destas definições podem-se reforçar as seguintes informações principais:

A contabilidade gerencial tem como foco o processo de tomada de decisão dos usuários internos, ou seja, deve atender todas as pessoas dentro da empresa, em qualquer nível hierárquico, que necessitam da informação contábil para tomar decisões em suas respectivas áreas;

A contabilidade gerencial é mais analítica, mais detalhada que a contabilidade financeira. A contabilidade financeira apresenta seus relatórios para os usuários externos em formatos sintéticos, em grandes números, como, por exemplo, o balanço patrimonial;

A contabilidade gerencial parte das informações existentes na contabilidade financeira e faz os complementos necessários para o uso dos gestores. Não tem modelos específicos de relatórios. As informações contábeis gerenciais devem ser apresentadas em relatórios desenvolvidos para cada tomada de decisão e adaptados para o perfil do usuário do relatório.

É neste ambiente complexo e de alta velocidade que as empresas precisam estar preparadas para lidar com as tomadas de decisões cada vez mais rápidas e difíceis, pois o tempo de resposta ao mercado será a diferença entre o sucesso e o fracasso. 
Para tanto, é necessário estar consciente e munido de informações confiáveis, claras, completas, econômicas e oportunas, ou seja, o suficiente para tomar a melhor decisão possível. Diante desses desafios, o tomador de decisões diário precisa identificar a melhor forma para entender o ambiente complexo e encontrar as melhores alternativas para se apoiar (HENRIQUE, 2008).

\subsection{O CONCEITO DA CONTABILIDADE}

Para buscar a compreensão sobre contabilidade gerencial é necessário entender o conceito de contabilidade. Sendo a contabilidade uma das ciências mais antigas da humanidade, seu objetivo principal é registrar informações econômicas, financeiras e demonstrar as alterações do patrimônio das empresas, servindo de base e auxiliando os administradores no processo decisório sobre destinação dos recursos (BARROS, 2013).

Barros (2013), conclui que:

Contabilidade é a ciência social que visa ao registro e ao controle dos atos e fatos econômicos, financeiros e administrativos das entidades. Trata-se de um sistema de informação e avaliação destinado a prover seus usuários com demonstrações e análises de natureza econômica, financeira, física e de produtividade, com relação à entidade objeto de contabilização.

Entende-se que a contabilidade, além de ciência social, é a técnica de registrar, interpretar, demonstrar e estudar todos os fatos que afetam o patrimônio das entidades, ou seja, seus bens, seus direitos e suas obrigações, fornecendo informações úteis para o processo definitivo (JIAMBALVO, 2013).

\section{2 ÁREAS DE ATUAÇÃO DA CONTABILIDADE GERENCIAL NAS EMPRESAS}

O aproveitamento da Contabilidade Gerencial dentro da empresa possibilita diversas informações, ajuda os gestores a tomarem decisões relativas a vendas, orçamentos, produção, planejamento, entre outros. Os gerentes das empresas industriais e das de

$\mathrm{RC}: 106869$

Disponível em: https://www.nucleodoconhecimento.com.br/contabilidade/beneficonas-empresas 
serviços, por estarem em um ambiente mais competitivo, carecem de informações gerenciais e relevantes sobre os seus custos efetivos, para auxiliarem seus engenheiros a projetarem produtos que possam ser fabricados eficientemente $e$, ainda, observar onde são necessários os aperfeiçoamentos em qualidade, eficiência e rapidez nas operações de fabricação, conduzir as decisões sobre seus produtos, escolher entre diversos fornecedores, negociar com clientes sobre preços diferentes, especificações dos produtos, entrega, qualidade e serviços (IUDíCIBUS, MARTINS, GELBCKE, 2003).

Os gestores necessitam de informações adequadas e integradas aos sistemas de informações, que permitam a comparação em todas as etapas do processo de gestão. A contabilidade é uma ciência social aplicada que, através de metodologia própria, o método das partidas dobradas, tem a finalidade de controlar o patrimônio e apurar os resultados das atividades das vendas (VICECONTI; NEVES, 2017).

Segundo ludícibus; Marion e Faria (2018, p. 34) o objetivo da contabilidade é "[...] o de fornecer informação estruturada de natureza econômica, financeira e, subsidiariamente, física, de produtividade e social, aos usuários internos e externos à entidade". Ou seja, a partir da contabilidade, o usuário tem subsídios para definir suas projeções e tomar as decisões com segurança, a partir de bases confiáveis, com o intuito de promover a continuidade do negócio. Jiambalvo (2013, p. 3) corrobora ao afirmar que o "objetivo da contabilidade gerencial é fornecer as informações necessárias para o planejamento, controle e a tomada de decisão." Essas informações serão obtidas "por meio do processamento da coleta de dados e informações que serão armazenadas e processadas no sistema de informações da empresa" (CREPALDI; CREPALDI, 2019, p. 3).

De acordo com Crepaldi e Crepaldi (2019), afirma-se "que a contabilidade gerencial auxilia os gestores com diversos instrumentos de cunho financeiro, econômica e patrimonial voltados à gestão do negócio, com um melhor aproveitamento dos recursos empregados". 
Neste contexto, são extraídos os dados da contabilidade financeira e a estes são somadas outras informações não financeiras e prospectivas, com o intuito de subsidiar o processo decisório.

\subsection{NECESSIDADES DAS INFORMAÇÕES}

Padoveze (2004, p. 52), explica que a informação deve ser tratada como qualquer outro produto que esteja disponível para consumo. Ela deve ser desejada para ser necessária e, para ser necessária, deve ser útil. Cabe aos contadores gerenciais criar essa mercadoria com qualidade e custos competitivos, já que se sabe de seu benefício e de sua necessidade para a manutenção dos negócios. Padoveze (2004) pondera que a necessidade da informação é estabelecida pelos usuários finais, ou seja, os consumidores. A informação deve ser composta para atender a esses consumidores e não para os contadores. O contador gerencial deve saber que essas informações, são elaboradas para atender as necessidades de outros. Os contadores gerenciais têm como objetivo buscar uma análise básica das informações a partir das decisões que serão tomadas com base no Sistema de Informação Contábil-Gerencial.

Nakagawa (1993, p. 59) estabelece uma distinção entre os dados e as informações. Os dados podem ser indicados como mensuração ou descrições de eventos ou objetos. Se estes dados são conhecidos ou não interessam aos indivíduos a quem são comunicados, não terão efeito de informação verdadeira. A informação contábil deve integrar-se aos demais sistemas informacionais da empresa, de modo que os dados diversos possam ser compartilhados e cruzados a fim de gerar relatórios específicos, que contribuam de forma fundamental para a análise e uma posterior tomada de decisão. O objetivo final do sistema de informação contábil é fornecer ao gestor informações valiosas que sirvam de apoio ao processo decisório.

Assim, conforme Marques (2004)

Os usuários das demonstrações fornecidas pelo Sistema de Informação Contábil são todas pessoas físicas ou jurídicas que tenham interesse na avaliação da situação e do progresso de

RC: 106869

Disponível em: https://www.nucleodoconhecimento.com.br/contabilidade/beneficonas-empresas 
determinada entidade, seja uma empresa, uma entidade de finalidades não lucrativas ou mesmo um patrimônio familiar, e nessa perspectiva que se aborda a contabilidade e o ambiente, ou seja, de que forma a contabilidade contribui para o ambiente global e de que maneira ele capta os dados externos para processá-los e transformalos em informações uteis para o processo de tomada de decisões.

Os gestores necessitam de informações adequadas para que seja permitido comparações em todas as etapas do processo de gestão e que sejam integradas com os sistemas de informações (SÁ, 2002).

\subsection{SISTEMAS DE INFORMAÇÃO DE APOIO À DECISÃO}

Há sistemas próprios idealizados para assessorar diretamente os gestores em suas decisões gerenciais, representando o refinamento dos sistemas de apoio à gestão. Estes são chamados de sistemas de suporte à decisão e de sistemas de informações determinadas. Ambos se aproveitam dos dados dos sistemas operacionais para se ter uma direção, seu foco é promover alterações de informações não estruturadas, para tomada de decisões (PADOVEZE, 2004, p. 51).

Conforme Figueiredo (1997, p. 34), o sistema de informação define como:

O propósito básico da informação é habilitar a organização seus objetivos pelo uso eficiente dos recursos disponíveis nos quais se inserem: pessoas, materiais, equipamentos, tecnologias, dinheiro, além da própria informação. A informação tem como objetivo principal à adequação do sistema de informação ao processo decisório, fornecendo informação cujas tendências sejam levar a decisões ótimas com relação ao resultado econômico, fazendo com os gestores, entre as várias alternativas, selecione aquela que aperfeiçoará o resultado: reduzindo custos aumentando receitas, aumentando lucro, aumentando eficiência, aumentando eficácia.

É importante que o empresário utilize o sistema de informação contábil gerencial para o processo de tomada de decisão. Para isso, é necessário que o profissional de contabilidade, esteja altamente capacitado e forneça dados que contribuam para resolução dos questionamentos internos, ou seja, dados que estabeleçam meios para que os gestores confiem nas informações geradas. 


\subsubsection{DEMANDA DA INFORMAÇÃO}

Segundo Crepaldi (2019, p. 15), o contador gerencial precisa ter o controle preciso das informações, auxiliando nas decisões tomadas com base no Sistema de Informação Contábil-Gerencial.

A informação pode ser determinada como dados ou conjuntos de elementos, que geram o efeito surpresa na pessoa que a recebe. Ademais, ela deve diminuir a incerteza, comunicar mensagem, ter valor elevado a seu custo e, ainda, deve conter resposta que auxilie o tomador de decisão (CREPALDI, 2019).

Conforme afirma Nakagawa (1993, p. 62), observa-se que nas empresas modernas ocorreram no mínimo três grandes modificações, as quais estão contribuindo sobremaneira para o aperfeiçoamento e eficácia gerencial, ou seja, para a gestão da empresa.

As três mudanças significativas citadas por Nakagawa (1993) são:

A gestão da empresa passou a ser feita sob uma abordagem sistêmica e as próprias técnicas gerenciais obtiveram um avanço considerável. A informação passou a ser tratada como um produto de um sistema planejado, de modo a torná-la disponível de acordo com as necessidades dos gerentes. Desenvolveram-se sistemas de informação, que suportam os processos de planejamento e controle dos gerentes, bem como, os sistemas operacionais de gestão das atividades de produção da empresa.

Esse processo pode ser caracterizado como preferencial, baseado em adequado sistema de informação. Antes, a informação era obtida através de fontes diversas, e os gerentes processavam essa informação com base em habilidades pessoais (CREPALDI, 2009).

\subsubsection{O PROCESSO DA TOMADA DE DECISÃO}

Padoveze (2004, p. 49) relata que, diante dos pressupostos básicos para se obter informações contábeis, é notório que a contabilidade, como ferramenta gerencial,

Disponível em: https://www.nucleodoconhecimento.com.br/contabilidade/benefico- 
transforma a ação administrativa, tornando um instrumento gerencial eficaz para a empresa.

É possível fazer uso da contabilidade gerencial em uma empresa, desde que se construa um sistema de informação contábil. Diante disso, se faz necessário sistemas gerenciais e operacionais, que sejam dotados de características que preencham todas as necessidades informacionais dos gestores para o gerenciamento (LACERDA, 2008).

O objetivo fundamental é fornecer informações de caráter financeiro, econômico, social e, de forma geral, informações gerenciais. Tais informações são relevantes ao se tomar decisões que afetam a entidade como um todo (FEDATO; GOULART; OLIVEIRA, 2003).

A Contabilidade gerencial busca informações internas que auxiliem na tomada de decisões, tanto internas, quanto externas, tendo como base dados da organização. Tais informações são importantes também no que diz respeito ao operacional da empresa. Com essa ferramenta é possível identificar falhas que comprometem o bom desenvolvimento da organização. Existem diversos fatores que levam ao crescimento da rotatividade das empresas, dentre eles destaca-se o aspecto gerencial, que tem papel de denunciar problemas de competência gerencial dentro ou fora da empresa, advindo desde fragilidades administrativas e organizacionais até a prática e costumes comuns considerados como forças restritivas ao seu desenvolvimento (LACERDA, 2008).

A contabilidade na tomada de decisão para transações tem sua estrutura formal do processo decisório baseada em princípios, definições e funções, que objetivam o apoio aos gestores na escolha certa para ação ter sucesso. Tendo como objetivo aperfeiçoar o resultado econômico das decisões sobre quaisquer transações que venham a causar impactos no patrimônio e nos resultados da empresa. A contabilidade é uma área de conhecimento utilizada como instrumento de auxílio à gestão das empresas, ou seja, é caracterizada por transformar grandezas 
heterogêneas em elementos com uma mesma base de representação, ao refletirem termos monetários e transações realizadas (PELEIAS, 2002, p. 78 - 79).

\section{CONSIDERAÇÕES FINAIS}

Este artigo procurou demonstrar a aplicação da contabilidade gerencial no processo de tomada de decisão empresarial. Ao verificar o objeto deste artigo, percebe-se que o profissional contábil que atua na função gerencial deve ter um amplo conhecimento nas diversas esferas contábeis, bem como do planejamento estratégico e da legislação tributária, para que possa atender a demanda da organização diante do mercado atual.

Observe-se que a contabilidade gerencial vem ganhando visibilidade na atualidade, pois é responsável por demonstrar informações indispensáveis à alta administração da empresa, tais como: auxílio a redução de custos, planejamento empresarial e estratégico, e ampliação da lucratividade. $O$ atributo existente no profissional de contabilidade é sua preocupação em amparar os gestores para que as empresas possam alcançar seus objetivos. A contabilidade preocupa-se em fornecer não apenas informações de natureza financeira, econômica e patrimonial, mas pretende atender as necessidades de seus usuários no processo de tomada de decisões.

Assim, em resposta à pergunta de pesquisa, conclui-se que a contabilidade gerencial não é responsável apenas por transmitir informações de cunho financeiro, econômico e patrimonial, mas também objetiva atender as necessidades de seus usuários no processo decisório. Assim, percebe-se a importância da contabilidade gerencial como ferramenta no processo de tomada de decisão.

Diante do exposto, infere-se que as informações providas pelo contador gerencial passaram a ser essenciais e benéficas para a tomada de decisão, uma vez que consideráveis alterações estão acontecendo na forma com que as empresas competem mutuamente. 
A pesquisa retificou características relevantes que podem oferecer benefícios aos usuários que fazem uso desta ferramenta. As informações fornecidas pela contabilidade gerencial podem auxiliar os gestores a melhorar a qualidade das operações, do planejamento e do processo de tomada de decisão da empresa.

Como a temática explorada não se esgota com este artigo, torna-se indispensável à continuidade para aprimorar a importância da contabilidade gerencial no processo de tomada de decisão, visando, acerca de tudo, informar aos gestores e aos demais usuários a arrumação econômico-financeira em que empresa se encontra no mercado.

\section{REFERÊNCIAS}

BARROS, M. Contabilidade Geral. [Apostila digital]. Fundação Sergio Contente. IDEPAC, 2013.

BERTUCCI, J.L.O. Metodologia básica para elaboração de trabalhos de conclusão de cursos (TCC): ênfase na elaboração de TCC de pós-graduação Lato Sensu. 1ㄹedição. São Paulo: Atlas, 2012.

CREPALDI, S.A.; CREPALDI, G.S. Contabilidade Gerencial: teoria e prática. 8. Ed. São Paulo: Atlas, 2019.

FEDATO, G.A.L.; GOULART, C.P.; OLIVEIRA, L.P. Contabilidade para Pequenas Empresas: na utilização da Contabilidade como instrumento de auxílio as micro e pequenas empresas. 2003.

FERREIRA, R.J. Contabilidade Básica: Finalmente você vai aprender contabilidade. 3. ed. Rio de Janeiro: Editora Ferreira, 2004.

FIGUEIREDO, S.; CAGGIANO, P.C. Controladoria Teoria e Prática. 2. Ed. São Paulo: Atlas, 1997. 
GIL, A. C. Métodos e técnicas de pesquisa social. 5. ed. São Paulo: Atlas, 1999.

GITMAN, L.J. - Princípios de Administração Financeira - $7^{a}$ Edição - Editora Harbra - São Paulo - 2000.

HENRIQUE, M.A. A importância da contabilidade gerencial para micro e pequena empresa. Dissertação. Universidade de Taubaté. São Paulo. 2008.

IUDÍCIBUS, S.; MARTINS E.; GELBCKE E.R. Manual de Contabilidade das Sociedades por Ações. 6. Ed. São Paulo: Atlas, 2003.

IUDÍCIBUS, S.; MARION, J.C.; FARIA A.C. Introdução à teoria da contabilidade: para graduação. 6. Ed. São Paulo: Atlas, 2018.

JIAMBALVO, J. Contabilidade gerencial. 3. Ed. Rio de Janeiro: Ltc, 2013.

LACERDA, J.B.. A contabilidade como ferramenta gerencial na gestão financeira das Micro, pequenas e Médias Empresas: necessidade e aplicabilidade. Revista Brasileira de Contabilidade. Ano XXXI, n 160.2008.

MARQUES, W.L. Contabilidade Gerencial à necessidade das Empresas. 2a edição. Paraná: Cidade, 2004.

MARION, José Carlos. Contabilidade empresarial. 11. Ed São Paulo: Atlas, 2005.

NAKAGAWA, M. Introdução à Controladoria: conceitos, sistemas, implementação. 1. Ed São Paulo: Atlas, 1993.

PADOVEZE, C.L. Contabilidade Gerencial. Curitiba: IESDE, 2012.

Contabilidade Gerencial: um enfoque em sistema de informação contábil. 4. Ed. São Paulo: Atlas, 2004. 
PELEIAS, I. R. Controladoria: gestão eficaz utilizando padrões. São Paulo: Saraiva 2002.

SÁ, A.L. Teoria da Contabilidade. 3. ed. São Paulo: Atlas S.A. 2002.

VICECONTI, P.; NEVES, S. Contabilidade Básica: 17. Ed. São Paulo: Saraiva, 2017.

Enviado: Agosto, 2021.

Aprovado: Fevereiro, 2022. 